\title{
Integrating mental skills into your coaching: A practical approach
}

\author{
Merlin van de Braam $^{\text {a }}$ \\ ${ }^{a}$ Lawn Tennis Association, London, United Kingdom.
}

\section{ABSTRACT}

Competitive tennis places a number of unique psychological demands on players. This article discusses some basic theoretical frameworks that coaches can use to underpin a practical approach to training mental skills as part of everyday squad training. The exercises outlined are specifically aimed to improve concentration, confidence, control of emotions and commitment.

\author{
Key words: mental skills; \\ psychology; on-court training. \\ Received: 15 February 2020 \\ Accepted: 02 May 2020 \\ Corresponding author: Merlin van \\ de Braam, National Tennis \\ Centre, 100 Priory Lane, \\ Roehampton, London, SW15 5JQ, \\ United Kingdom. Email: \\ Merlin.van-de-braam@Ita.org.uk
}

\section{INTRODUCTION}

Competitive and professional tennis places many demands on athletes from a psychological perspective. There are no substitutions permitted, coaching is not allowed during a match and unlike most team sports, the duration of competition can vary significantly. At the regional and national level, players are required to both compete and also officiate their matches. At the higher end of the game, most players ranked inside the world's top 150 in both male and female tennis lose more matches than they win in an average season (ATP, 2020; WTA, 2020). Analysis by O'Shannessy (2018) has also shown that tennis players must learn to cope with high amounts of loss, with the world's top 10 players winning on average just $53 \%$ of the points they play in a year.

\section{MENTAL SKILLS}

There are a number of frameworks and publications that have been developed in an attempt to facilitate the training of mental skills within athletes across a range of sports, including football (Harwood, 2008) and tennis (Crespo, Reid \& Quinn, 2005).

The "5C's framework" (Harwood, 2008) positions mental skills as trainable, and suggests that coaches can play a key role their development. The specific skills cited within this framework and by the ITF Tennis Psychology manual are Commitment (motivation), Concentration, Control (of emotion), Confidence and Communication.

\section{MENTAL TOOLS}

Applied sport psychologists and coaches utilize a number of strategies, techniques or 'tools' to enhance performance and the mental skills in their athletes. There are a number of well documented and empirically tested tools that can be specifically used to develop and support the aforementioned mental skills. These tools include, but are not limited to;
1. Goal setting
2. Visualisation
3. Self-talk
4. Breathing

To understand the relationship between mental skills and mental tools, it is helpful to use the analogy of physical development. In explanation, running could be employed as the physical 'tool' that develops the physical 'skill' of endurance. Similarly, stretching can be used as a tool that develops the skill of flexibility.

In the context of mental skills, if a coach would like to develop confidence, the use of goal-setting could be employed to foster this. Confidence can be derived from the experience of completing a specific, measurable but challenging target e.g. an increase in ranking (outcome goal). 
In a practical on-court setting, one mental tool can be used to develop more than one mental skill. For example, goal setting can also be used to develop concentration by providing focus and direction for an athlete within a point, match or training block/season.

\section{PRACTICAL EXERCISE FOR DEVELOPING CONCENTRATION}

Reading the ball

Players rallying from the baseline must concentrate on the flight path of the oncoming ball, and shout verbally if they think the ball will land short or deep before it bounces. Coaches can progress this to be more difficult by splitting the court into three segments, or by challenging the player to predict the bounce of the ball before it crosses the net. Coaches can adapt this drill in a number of ways, including asking players to 'read' the oncoming spin of the ball.

\section{How does this exercise help to develop concentration?}

Concentration can be seen as a mental spotlight (Kremer \& Moran, 2008). This exercise directs a player's attention to relevant cues, which in this case is the flight path and speed of the oncoming ball. Directing concentration to relevant cues can lead to improved anticipation and movement in preparation for the next ball.

\section{PRACTICAL EXERCISE FOR DEVELOPING CONTROL OF EMOTIONS}

Serve nerve

Players can compete against each other working in pairs on the same baseline. For this drill, players hit serves only. A total of four $1^{\text {st }}$ serves need to be hit in a row to win a game. The player should serve from alternating sides after each successful serve. If a player misses a serve, then they are required to step away to give the opponent a chance to 'hold their nerve' and hit four first serves in a row. Players can be instructed to complete a full set.

\section{How does this help to develop control of emotions?}

This exercise is proposed to provide an environment for the player to test their emotional control under pressure. Specifically, the consequences of a missed serve increase incrementally after each successful serve. A player who has hit three successive first serves for example, will feel pressure building up to make the final serve to close out a game. Alongside this exercise, coaches can introduce positive selftalk to the player's normal service routine. The hypothesis here is that by using positive self-talk, players are less likely to experience negative thoughts or feelings that that have been shown to result in lower serve consistency (Van de Braam \& Moran, 2011)

\section{PRACTICAL EXERCISE FOR DEVELOPING COMMITMENT}

Dice tennis

This exercise requires players to play six competitive points to simulate the duration of one average game in tennis. Upon the conclusion of all six points, players are required to come to the net and roll an oversized foam dice. The player that wins the game is the player that won the point that corresponds to the number rolled by the dice. For example, if a player won the $1^{\text {st }}$ and $5^{\text {th }}$ point only and the dice roll was 1 or 5 , this player will win the game, despite the fact that they won less points, and lost the last point played.

\section{How does this exercise help to develop commitment?}

This exercise aims to teach players that they should commit and fight for every point within a match. The use of a Dice introduces random allocation of victory and therefore the game can be won by either player, not the player that won the last point in the game, which is the norm in tennis. This results in players learning to fight for each point because they are of equal importance due to the introduction of the Dice. Whilst this exercise does not develop long-term motivation or underlying constructs linked to lasting commitment, it is a fun approach to competition that teaches players a valuable lesson to compete for each point.

\section{PRACTICAL EXERCISE FOR DEVELOPING CONFIDENCE}

\section{Marathon tennis}

Players or coaches need to select a process (e.g. recover offcentre during a forehand cross-court exercise). During the exercise, the player calls out loud if they achieve this task (by crossing a marker on the ground. Players accumulate a point for every successful execution of this specific process. They player that goes on to win the point receives a number of points that corresponds to how many times they executed the process. The player that loses is awarded half the points based on how many task completions. The objective of the exercise is to reach 26 points first - the equivalent of a marathon in tennis.

\section{How does this exercise help to develop confidence?}

Research shows that players whose perceptions of success are based on personal best (task orientation), alongside winning (ego/outcome orientation) are more motivated, show more persistence in the face of adversity, and demonstrate less competitive anxiety. This exercise teaches players that whilst the outcome of the point is important (did you win?), it also emphasizes the importance of the process (how did you 
win?). In the current exercise, quality is the process that would result in scoring more points. Winning the point without completing the process can only yield one point at a time.

\section{GENERAL CONSIDERATIONS FOR INTEGRATING MENTAL SKILLS INTO YOUR COACHING}

1. Structure the training environment in a way that enables mental skills to be tested and developed every day - in a fun and positive manner

2. Always look to create player ownership, autonomy and independence - ask effective questions to involve your player in the learning journey and listen more than you speak.

3. Create an environment and communicate in a way that values a player's personal best, alongside beating others

4. Do not use 'mental toughness' training as an excuse for bullying, intimidation or any other inappropriate behaviour that may harm athlete well-being and their enjoyment of tennis

5. Know your limits as a tennis coach: ensure that you refer or recommend players to engage chartered sport psychologists or clinical psychologists where you detect a significant issue, such as a potential eating disorder or extreme levels of competitive anxiety https://www.braingametennis.com/

Van de Braam, M. \& Moran, A. (2011). The prevalence and effects of negative mental imagery in tennis. Journal of medicine and science in tennis, 16, 34-37.

WTA (2020, February 15) WTA Stats Hub. Retrieved from https://www.wtatennis.com/stats

RECOMMENDED ITF TENNIS ACADEMY CONTENT (CLICK BELOW)

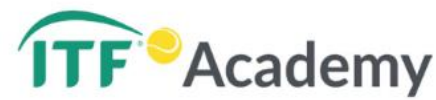

Copyright (c) 2020 Merlin van de Braam

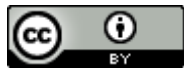

This text is under a Creative Commons BY 4.0 license

You are free to Share - copy and redistribute the material in any medium or format - and Adapt the content - remix, transform, and build upon the material for any purpose, even commercially under the following terms:

Attribution: You must give appropriate credit, provide a link to the license, and indicate if changes were made. You may do so in any reasonable manner, but not in any way that suggests the licensor endorses you or your use.

CCBY 4.0 license terms summary CCBY4.0 license terms

\section{CONCLUSION}

Concentration, commitment, confidence and control of emotion are all skills that an athlete needs to navigate the unique psychological demands of tennis. Developing these skills through the use of mental tools, embedded into on-court exercises, can provide a fun and innovative way to enhance the efficacy of your coaching sessions. It is hoped that using these well-established mental skills and mental tools frameworks within tennis will lead to an increase in the amount of time spent training what is traditionally the most neglected of performance factors in tennis.

\section{REFERENCES}

ATP (2020, February 15). ATP statistics leaderboard. Retrieved from https://www.atptour.com/en/stats

Crespo, M., Reid, M., Quinn, A. (2005). Tennis Psychology: Practical drills and the latest psychology research. ITF, London.

Harwood, C. (2008). Developmental Consulting in a Professional Football Academy: The 5Cs Coaching Efficacy Program. The Sport Psychologist, 22, 1, https://doi.org/10.1123/tsp.22.1.109 Kremer, J. \& Moran, A. (2008). Pure Sport: Practical Sport Psychology. Routledge, London.

O'Shannessy, C. (2018). Brain Game Tennis. 